\title{
Problema, sentido e significado: a multiplicidade em Modelagem Matemática
}

\author{
Problem, meaning and significance: \\ the multiplicity in Mathematical Modeling
}

Tiago Weingarten ${ }^{1}$. Rodrigo Dalla Vecchia ${ }^{2}$

\begin{abstract}
Resumo: Este artigo tem como objetivo discutir a multiplicidade de possibilidades para determinação de problemas inerentes à Modelagem Matemática, quando a problemática investigada parte do interesse dos estudantes. Adentro ao contexto, buscaremos compreender os aspectos referentes ao entrelaçamento entre problema, sentido e significado representados pelas proposições. O contexto de pesquisa envolveu problemas oriundos do cotidiano dos alunos matriculados nas disciplinas de Pesquisa Operacional I e II do curso de Engenharia de Produção de uma universidade do estado do Rio Grande do Sul. A Abordagem metodológica foi qualitativa. Como principal resultado destacamos o papel do propositor do problema e a influência do sentido como orientador do processo de determinação do problema frente às potenciais multiplicidades de encaminhamentos apresentadas pelas significações conceituais.
\end{abstract}

Palavras-chave: Educação matemática. Proposição. Transformação. Modelagem matemática.

\begin{abstract}
This article aims to discuss the multitude of possibilities for problem determination related to mathematical modeling, through the interest of students in problematic investigations. In our context, we seek to understand aspects related to the intertwining of problem, meaning and significance represented by propositions. The research involved problems coming from the context of everyday students enrolled in the courses of Operations Research I and II of the course of production engineering at a university in the state of Rio Grande do Sul. The methodological approach was qualitative. The main result we highlight is the role of proposer of the problem and the influence of sense as guiding the process of determining the opposite problem to potential multiplicities of referrals made by conceptual meanings.
\end{abstract}

Keywords: Mathematics education. Proposition. Transformation. Mathematical modeling.

\footnotetext{
${ }^{1}$ Universidade Luterana do Brasil (ULBRA), Programa de Pós-graduação em Ensino de Ciências e Matemática, Canoas, RS, Brasil. E-mail: <tiago_weingarten@hotmail.com>.

${ }^{2}$ Universidade Federal do Rio Grande do Sul (UFRGS), Departamento de Matemática Pura e Aplicada, Porto Alegre, RS, Brasil.
} 


\section{Introdução}

Ao olhar de modo atento para a Modelagem Matemática (MM), é possível observar que a mesma se mostra de modo múltiplo, abarcando distintas formas de ser compreendida (ANASTACIO, 1990; DALLA VECCHIA, 2012; KLÜBER, 2012; MALTEMPI; DALLA VECCHIA, 2013). Autores como Kaiser e Sriraman (2006) fazem uma revisão de literatura e apresentam cinco caracterizações distintas para a MM: a realistica, na qual as situações analisadas são retiradas da indústria e da ciência e foca sua atenção para o desenvolvimento de habilidades relacionadas à resolução de problemas aplicados; a epistemológica, cujo objetivo está relacionado com o desenvolvimento de teorias matemáticas; a educacional, que, em termos gerais, associa a realística e a epistemológica integrando situações-problema autênticas visando às teorias matemáticas; a contextual, na qual as situações se destinam à construção de conceitos matemáticos, mas são sustentadas por estudos psicológicos; e a sócio-crítica, que procura desenvolver situações nas quais o papel dos modelos na sociedade possa ser discutido.

Nesse universo, parece haver alguns aspectos que perpassam essa multiplicidade e estão presentes de modo implícito ou explícito nas visões que abrangem a MM. Dentre esses aspectos, consideramos fundamental a ideia de problema. Autores como Araújo (2002, p. 20, grifo nosso) afirmam que, de modo geral, a MM, “[...] independente do contexto em que está presente, tem como um de seus objetivos a resolução de algum problema da realidade ${ }^{3}$ por meio do uso de teorias e conceitos matemáticos".

Esse aspecto pode ser observado, por exemplo, em Ferri e Blum (2010), que apresentam uma visão clássica e comumente aceita no cenário investigativo de como ocorre a Modelagem Matemática (MM). Na perspectiva desses autores, a MM é vista como um ciclo e denotada por ciclo de modelagem (Figura 1), que parte de uma situação real problemática. Nessa forma de conceber a MM, há um conjunto de passos que são seguidos e iniciam após a tarefa ser dada. O primeiro passo é, segundo os autores, imaginar a situação construindo um modelo para a mesma. Essa situação é simplificada, estruturada e idealizada, criando-se associações entre a situação investigada e a matemática. Após essa idealização, a estrutura é vista sob a perspectiva da matemática e trabalhada matematicamente até encontrar resultados, também matemáticos. Esses resultados são interpretados na situação real, sendo validados ou não. Se não forem validados, o ciclo recomeça; caso contrário, o processo se encerra com a exposição do resultado obtido.

\footnotetext{
${ }^{3} \mathrm{Em}$ nossas ideias, trazemos uma visão distinta de realidade, que aborda o atual e o não atual como base para a discussão entre a relação da matemática com a realidade mundana. 
Figura 1. Ciclo de modelagem sob uma perspectiva cognitivista

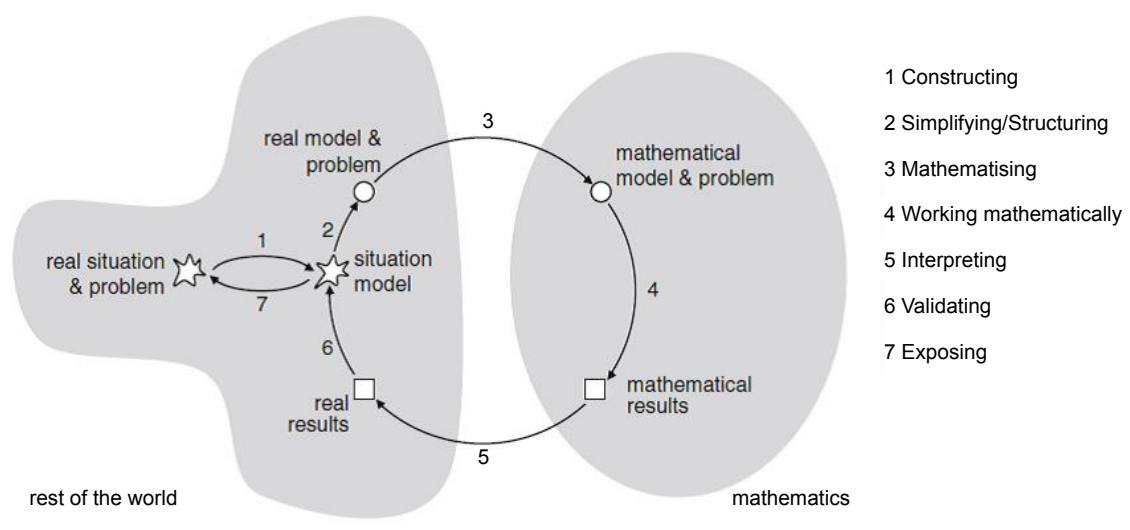

Fonte: Ferri e Blum (2010, p. 426).

Com pequenas variações dessas visões, podemos, ainda, acrescentar autores como Bassanezi (2004), Biembengut e Hein (2007) e Kaiser, Schwarz e Tiedemann (2010) que, de um modo geral, mostram o aspecto apontado por Araújo (2002), iniciando todo o processo a partir de uma situação problemática e culminando com uma solução por meio de um modelo matemático.

Apesar de não discordarmos totalmente das visões de autores que determinam a MM como ciclos ou como sequenciamentos pré-definidos de etapas, nossos resultados têm mostrado que o processo de MM pode abranger modos diferentes de se mostrar, seguindo caminhos não necessariamente lineares (DALLA VECCHIA, 2012; DALLA VECCHIA; MALTEMPI, 2012). Na busca por compreensões acerca dos desdobramentos que a MM pode sofrer nos questionamos: quais os principais aspectos que influenciam a MM? Até o momento de escrita deste artigo, entendemos ser possível observar a MM de modo fluido e em constante transformação. Essa fluidez se mostra principalmente por meio do entrelaçamento de quatro aspectos considerados relevantes: objetivo pedagógico, modelos/linguagem, problema e realidade. De modo alegórico, entendemos que as características múltiplas de cada um desses aspectos se entrelaçam, influenciando o processo de $\mathrm{MM}$ do mesmo modo que pedras atiradas em um lago de águas paradas influenciam as suas ondulações (Figura 2). 
Figura 2. MM vista como um fluxo que se desdobra por meio da multiplicidade dada pelo modelo, pelo problema, pelo objetivo pedagógico e pela realidade

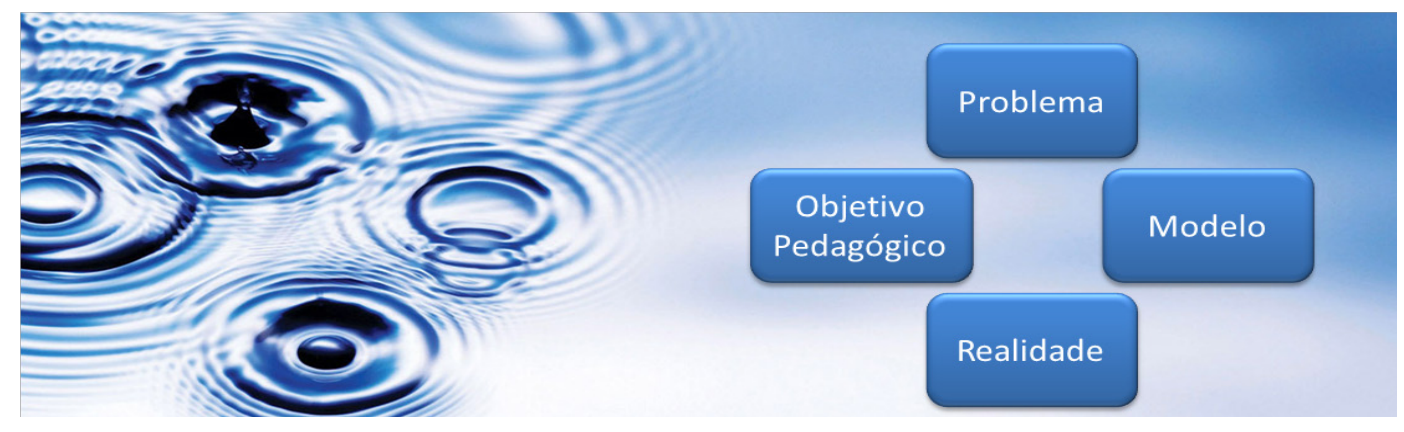

Fonte: Dalla Vecchia (2012, p. 217).

Ao visualizar a Figura 2, é possível observar que as ondulações não formam um campo isolado, mas sim campos que se afetam, formando fluxos. Avaliada por meio dessa perspectiva, a MM pode ser vista como um processo que não se mostra estático, pois qualquer alteração pode influenciar de modo decisivo o encaminhamento na busca de uma solução para o problema. No que diz respeito aos quatro aspectos apresentados, entendemos por objetivos pedagógicos como sendo "[...] o conjunto de fins ou metas que se deseja atingir quando se desenvolve qualquer tipo de proposta com os alunos que visa a contribuir para o processo educacional” (DALLA VECCHIA, 2012, p. 71). As caracterizações apresentadas no início dessa introdução por Kaiser e Sriraman (2006) mostram de modo indireto que diferentes objetivos podem implicar diferentes formas de compreender a MM e, consequentemente, de conduzir o processo.

Em relação ao modelo, consideramos que aspectos como a simbologia utilizada (tipo de matemática e sua relação ou não com linguagens computacionais), a finalidade a que o modelo se destina e a sua relação com a realidade são aspectos que podem contribuir para que uma mesma situação problemática possa ser avaliada por meio da matemática de modo múltiplo (MALTEMPI; DALLA VECCHIA, 2013).

Outro aspecto importante é a realidade. Com o advento das Tecnologias Digitais (TD), a discussão acerca do real se potencializa, gerando adjetivações como realidade do ciberespaço, realidade do mundo cibernético, realidade aumentada, hiper-realidade ${ }^{4}$, realidade virtual, etc. Esse espaço, denotado muitas vezes por virtual, é diferenciado, permitindo e possibilitando ações e interações que se diferem na espacialidade e na temporalidade comumente vividas no cotidiano. Autores como Bicudo e Rosa (2010) trazem uma detalhada argumentação filosófica,

\footnotetext{
${ }^{4}$ A hiper-realidade é um aspecto discutido por Baudrillard (1991) e trata do simulado como algo que é abrangido pela realidade mundanamente vivida, porém se mostra em um campo que avança na medida em que a contradição entre o imaginário e o real vai sendo minimizada. Segundo esse autor, a hiper-realidade pode ser associada a simulações que não necessariamente possuem um referencial, um território ou uma substância e residem em um campo dado pela entrada do imaginário.
} 
em particular, fenomenológica, construindo argumentos para considerar o mundo criado pelas TD como uma das dimensões da realidade. Dadas as distinções qualitativas que esse espaço possui, considerá-lo como espaço de referência para construção e atualização de modelos pode implicar mudanças tanto na condução de atividades quanto de cunho ontológico frente à compreensão da própria MM.

Por último, e foco deste artigo, está a ideia de que o modo como o problema é compreendido pode conduzir, de modo definitivo, todo o processo. Em nossas investigações, temos tratado situações que são trazidas pelos alunos nas quais nem estudantes nem professores conhecem soluções a priori. A dinâmica desse processo envolve um fluxo de desdobramentos constante e, a cada nova interação entre os participantes do processo de modelagem, múltiplas novas possibilidades podem se apresentar.

Para compreender esse processo, embasamo-nos na visão de Deleuze (1988) o qual afirma que o problema não se subordina a nenhuma proposição referente a ele, e a forma como o problema é descrito mostra apenas uma das potenciais interpretações para ele, subordinada ao contexto histórico-social e à linguagem usada para sua determinação. Avaliar o problema sob esse ponto de vista implica considerar toda proposição como uma espécie de "resposta", isto é, como um campo vetorial que conduz o processo na direção de uma solução. Em outras palavras, diferentes modos de compreender o problema podem conduzir a diferentes soluções.

Essa determinação, segundo Deleuze $(1988,2011)$, não é estática, mas sim fluida e pode somente ser compreendida ao longo do próprio processo de solução da situação problemática. Em termos de MM, esse processo pode criar fluxos que são gerados, discutidos, assumidos ou abandonados, mostrando, conforme Weingarten (2015), um processo dinâmico de constante transformação que não necessariamente se subordina a uma linearidade pré-definida.

Não somente no caso abordado no presente artigo, mas em nossas investigações anteriores (DALLA VECCHIA, 2012; WEINGARTEN, 2015; WEINGARTEN, DALLA VECCHIA, 2015), vimos que as discussões dos envolvidos no processo de MM podem gerar múltiplas possibilidades de caminhos. Nessas pesquisas, alguns "caminhos" do fluxo eram assumidos. Outros não. Nesse sentido, nos questionamos: o que leva a assumir um caminho em vez. de outro(s)? Quais as características que podemos encontrar nos caminhos que não foram seguidos? E nos que foram seguidos? Ou, de modo similar e mais específico: que aspectos são os responsáveis pela condução do fuxo de determinação do problema ao longo do processo de $M M$ ? Sucessivas reflexões acerca desse assunto geraram a pergunta diretriz: Como se dá o processo de transformação da determinação do problema em Modelagem Matemática quando as situações investigadas partem das vivências dos estudantes?

Para construir possíveis respostas a esta pergunta, inspiramo-nos nas ideias de sentido e significado trazidas por Deleuze (2011) ao refletir sobre as dimensões assumidas por uma proposição. Dada a amplitude que este tema pode assumir, faremos neste artigo um recorte de nossa investigação, focando em aspectos específicos relativos aos desequilíbrios entre sentido e significado ${ }^{5}$ e sua influência no encaminhamento do processo de determinação do problema.

\footnotetext{
${ }^{5}$ Em termos gerais, o significado pode ser entendido como a possibilidade de um signo referir-se a seu objeto (ABBAGNANO, 2007). Esse aspecto será abordado tangenciado por Deleuze (2011) por meio da ideia de significação, exposta posteriormente nesse artigo.
} 
O paradigma metodológico assumido é o qualitativo. Os dados foram produzidos durante as aulas das disciplinas de Pesquisa Operacional I (POI) e Pesquisa Operacional II (POII) do curso de Engenharia de Produção, ocorridas no primeiro e no segundo semestre de 2013, respectivamente. Iniciaremos as discussões apresentando a visão de problema assumida na investigação.

\section{Referencial teórico}

Na perspectiva de problema que assumimos, o mesmo não pode ser confundido com a proposição que o representa. Essa visão é apresentada por Deleuze (1988). Para esse autor, o problema assume uma existência virtual e pode ser atualizado por meio de proposições de múltiplas maneiras. A analogia que fazemos para esclarecer essa afirmação é a mesma da relação entre uma paisagem, vista pelo pintor, e o quadro desenhado pelo mesmo. Assim como a tela pintada não é a situação vista, mas sim uma representação da mesma, a proposição não é o problema, mas uma forma de apresentá-lo. Portanto, devem ser levados em consideração os aspectos da linguagem usada para a representação, os aspectos que dizem respeito ao problema em si e o modo como o problema é interpretado pelos sujeitos que buscam sua determinação, isto é, a proposição que a ele se refere.

Essa proposição, ou o modo como o problema é expresso, é considerada uma forma de conduzir o problema, já indicando possíveis respostas e o caminho pelo qual o problema vai se desvelar. Nesse sentido, Deleuze (1988, p. 265) afirma:

Por si mesma, uma proposição é particular e representa uma resposta determinada. Um conjunto de proposições pode distribuir-se de tal maneira que as respostas que elas representem formem os casos de uma solução geral (assim, os valores de uma equação algébrica). Mas, precisamente, gerais ou particulares, as proposições só encontram sentido no problema subjacente que as inspira.

Com essa afirmação, esse autor mostra uma visão de problema anterior à proposição que o representa. Porém, a nosso ver, a noção de "resposta" que a proposição assume está diretamente associada à ideia que esse filósofo traz de pergunta. De modo geral, aponta que não considera existir uma biunivocidade entre problemas e questões, mas ressalva a importância da pergunta como orientadora, como uma espécie de condutor na direção da solução. Em outras palavras, a pergunta

[...] exprime, portanto, a maneira pela qual um problema é desmembrado, cunhado, traído na experiência e pela consciência, de acordo com seus casos de solução apreendidos como diversos. Embora nos dê uma ideia insuficiente, ela nos inspira, assim, o pressentimento do que ela desmembra. (DELEUZE, 1988, p. 257).

Esse papel que a pergunta assume, conforme Deleuze (1988), está sempre atrelado ao quadro social de onde parte a inquietação, trazendo pontos de vista, considerando a experiência 
vivida e os possíveis interlocutores, levando em consideração as respostas passíveis de serem dadas. Deleuze (1988, p. 267) não apenas distingue o problema no modo como é representado, mas também analisa a relação existente entre este e sua solução, pois afirma que um “[...] problema se determina ao mesmo tempo em que é resolvido; mas sua determinação não se confunde com a solução: os elementos diferem por natureza, e a determinação é como a gênese da solução concomitante". Para compreender essa afirmação, é importante salientar que, em suma, o problema é considerado por esse autor como uma estrutura potencial ou não atual. À medida que há uma imersão do sujeito no problema, há uma busca por sua determinação, que pode ser entendida, grosso modo, como uma espécie de atualização do problema, em termos de linguagem, sob a forma de proposições (interrogativas, afirmativas, descritivas, etc.). Entretanto, o modo como é expresso já influencia e conduz a busca por soluções, isto é, a determinação do problema é o início, é a gênese que norteia a busca por uma solução.

Mas essa determinação é apenas um caso particular do problema, podendo haver outras formas de interpretar e conceber a situação que está sendo investigada. Desse modo, distintas formas de conceber a situação podem levar a distintos encaminhamentos, podendo gerar distintas soluções.

Esse modo de compreender o problema traz como consequência a existência de um complementar que sempre foge ao signo ${ }^{6}$ e ao expresso quando se trata de procurar um modo de expressá-lo. Por outro lado, não há outro caminho para apresentar o problema, em termos linguísticos, senão por meio da proposição (falada, escrita) que o determina. Sendo assim, decalcamos nossa atenção na compreensão da proposição. Entretanto, não se trata de apenas apreender o significado das proposições, mas, sim, verificar se este conjunto estabelece sentido perante o problema, pois "[...] as proposições só encontram sentido no problema subjacente que as inspira”. (DELEUZE, 1988, p. 265).

Nesse contexto, entendemos haver um entrelaçamento entre o problema, o significado e o sentido, intermediado pelas proposições. Para Deleuze (1998), nenhum desses três conceitos pode ser restringido à proposição, mas, ao mesmo tempo, de forma indireta, necessitamos das proposições para garantir a existência destes, até mesmo seu entrelaçamento. Este devir entre propor e não uma situação garante que todo o problema é resolvível e insolúvel ao mesmo tempo (DELEUZE, 2011), garantindo a atemporalidade deste conceito. Logo, as proposições e os significados estabelecidos devem aludir ao problema, fomentando o sentido em todo o processo problemático, incluindo, na especificidade da pesquisa, as determinações envolvendo o processo de Modelagem Matemática.

A proposição, de acordo com Deleuze (2011), opera em quatro dimensões: designação, manifestação, significação e sentido. Embora em nossas pesquisas consideremos todas, focaremos, neste artigo, apenas as dimensões relacionadas ao significado e ao sentido.

A significação ${ }^{7}$ é entendia por Deleuze (2011) como a relação existente entre a palavra com conceitos universais ou gerais e das ligações sintáticas com implicações de conceito.

\footnotetext{
${ }^{6}$ Para Deleuze (2011), o signo remete à essência etimológica do significante, independendo do sujeito. No atual momento, em nossas pesquisas, adotamos o signo em alusão à simbologia matemática utilizada no desdobramento dos problemas.
} 
Sob esse aspecto, os elementos de uma proposição são sempre considerados significantes do conjunto de implicações de conceitos que podem remeter a outras proposições, que podem servir de premissas à primeira. Para Deleuze (2011, p. 15), a significação “[...] se define por esta ordem de implicação conceitual em que a proposição considerada não intervém senão como elemento de uma 'demonstração', no sentido mais geral da palavra, seja como premissa, seja como conclusão”.

Para Deleuze (2011, p. 20), o sentido é o “[...] expresso da proposição, este incorporal na superfície das coisas, entidade complexa e irredutível, acontecimento puro que insiste ou subsiste na proposição". Essa insistência e subsistência implica uma inferência que não ocorre de modo direto, mas indireto, dada na ordem da compreensão dos desdobramentos das demais dimensões, designação, manifestação e significação. Em outras palavras, “[...] podemos [...] tomar o sentido, isto é, o exprimido de uma proposição, como o designado de uma outra proposição, da qual, por sua vez, não dizemos o sentido, e assim indefinitivamente". (DELEUZE, 1988, p. 152). Dessa forma, ao mesmo tempo em que o sentido reside na proposição (é a proposição que deve fazer/ter sentido ou não), não é possível descrever o sentido por meio da própria proposição ${ }^{8}$, sendo necessário apresentá-lo em outra. Desse modo, o sentido, para Deleuze (2011), assegura a gênese de todas as outras dimensões da proposição, mesmo sendo "[...] irredutível [...] aos estados de coisas individuais, às imagens particulares, às crenças pessoais e aos conceitos universais e gerais". (DELEUZE, 2011, p. 20).

É importante ressaltar que, para discutir sentido, é preciso, ainda, avaliar o dito sob um ponto de vista que extrapola a proposição e suas relações e assume a dimensão do problema. Conforme Deleuze (1988, p. 154), o “[...] sentido está no próprio problema”. O problema, nesse caso, é quem orienta, quem conduz todo o processo proposicional, orientando o processo de produção das sentenças por meio do sentido. A pergunta que se deve proferir ao se apoiar nessas ideias não é faz sentido?, mas, sim, faz sentido para o problema?

\section{Metodologia}

Perseguindo elucidações para nossa pergunta norteadora: como se dá o processo de transformação da determinação do problema em Modelagem Matemática quando as situações investigadas partem das vivências dos estudantes? a presente pesquisa assume caráter qualitativo. Esta perspectiva de pesquisa consolida-se nas ideias de Gamboa (2012, p. 60), o qual afirma que o modo qualitativo de ver as informações resulta em um desenvolvimento científico voltado à investigação, “[...] visando maiores esclarecimentos sobre as visões de mundo e os interesses cognitivos que comandavam as práticas da pesquisa em educação" (GAMBOA, 2012, p. 60).

\footnotetext{
${ }^{7}$ Segundo Deleuze (2011), podemos considerar a significação como uma organização de um regime de signos produzidos pela existência ou pela situação.

${ }^{8}$ Conforme Deleuze (1988, p. 151), “[...] nunca dizemos o sentido daquilo que dizemos".
} 
Neste artigo, procuraremos compreender o processo das relações estabelecidas entre os alunos e as situações-problema. Assim, a preocupação se dará com o contexto laboral, buscando nas orientações teóricas a análise da realidade intelectualmente construída por cada aluno. $\mathrm{O}$ nosso interesse, como educadores, recai, também, no estudo das práticas pedagógicas envolvidas e nas relações da discência no Ensino Superior com o contexto empregatício dos alunos.

Segundo Ramos (2009), a pesquisa deve moldar a transformação do conhecimento em ações significativas, práticas e úteis. Na presente investigação, por ser tratar de um estudo pontual e exploratório, somos impedidos de assumir uma postura enrijecida e metódica. Desta forma, a busca pela compreensão dos desdobramentos da determinação do problema durante o processo de MM se dará analisando o entrelaçamento entre sentido e significado atrelados aos aspectos objetivos e matemáticos associados à problemática estudada. Consideramos importante ressaltar que as possíveis associações desses aspectos não permitem generalizar o processo problemático de modo a reproduzi-lo indefinidamente, pois, conforme Deleuze (1988), um problema só pode ser determinado enquanto da sua solução. Todavia, as determinações dos aspectos objetivos e matemáticos permeiam o processo fomentado pelo sentido, atuante como um vetor em direção da solução (DALLA VECCHIA; MALTEMPI, 2012) e, por conseguinte, da determinação do problema.

Perseguindo elucidações para responder à pergunta norteadora, no recorte considerado, consentimos que o processo problemático não se apresenta de forma necessariamente linear, assumindo, então, a visão de Dalla Vecchia (2012, p. 125) concernente à MM, perante a Educação Matemática (EM), constituída como “[...] um processo dinâmico e pedagógico de construção de modelos sustentados por ideias matemáticas que se referem e visam encaminhar problemas de qualquer dimensão abrangida pela realidade".

A potente instabilidade do processo problemático também se instaura na problemática de investigação mostrando-se consonante com as ideias de Ramos (2009, p. 37) acerca de uma pesquisa, pois este a considera “[...] virtualizada, desterritorializada e atemporal [...]", transcendendo o processo metodológico estático e linearmente construído como uma mera reprodução de conhecimentos. Nesse contexto, a busca pelo sentido das ações dependerá de como os aspectos objetivos, subjetivos e matemáticos atuarão no processo problemático no caso a ser estudado, conferindo pontualidade à pesquisa.

Para apreciação dos dados, examinaremos excertos das conversações entre os alunos durante as aulas de Pesquisa Operacional I (PO) e Pesquisa Operacional II, do curso de Engenharia de Produção, em uma universidade do Rio Grande do Sul. A disciplina de PO I foi ofertada no primeiro semestre de 2013 e a disciplina de PO II, no segundo semestre de 2013. A turma de PO I estava formada por 36 alunos e a turma de PO 2, por 32 alunos, sendo os estudantes, na sua grande maioria, os mesmos em ambas as turmas. As disciplinas de PO I e PO II estão relacionadas à aplicação da matemática para a otimização de processos industriais que, em determinado momento, serão sugeridos pelos alunos, baseados em suas experiências ou necessidades profissionais.

Os dados para esta pesquisa foram obtidos de gravações. Estas foram feitas por meio de dois modos de captura distintos: o Camtasia Studio ${ }^{\circledR 9}$, que se caracteriza como sendo um software para computadores no qual é possível a gravação de áudio e vídeo; e uma filmadora para gravação de vídeos. Almejando um entendimento aprofundado sobre a forma como o sentido influencia no processo problemático, realizamos as transcrições das gravações dos dados. No 
presente artigo, esta análise se constituirá na observação apurada de parte dessas transcrições, buscando frisar os elementos referentes à transformação da determinação do problema no decorrer do processo problemático. Após estas transcrições, foram selecionados os excertos das falas que contribuíram, em nosso entendimento, para tangenciar a pergunta diretriz.

Em consonância com nosso referencial teórico, atentaremos para o processo de construção dos modelos que surgiram por meio dos desdobramentos de todo contexto problemático, constituído aqui de forma a contemplar as ambições tanto dos alunos quanto do professor. Os alunos, por si só, almejam solucionar os problemas de suas empresas e, também, obter sucesso na disciplina. Por sua vez, o professor tem outros objetivos, entre eles o matemático e o pedagógico. Conforme mostraremos, os objetivos, seja por parte dos alunos, seja por parte do professor, forneceram o sentido ao processo de determinação do modelo, fomentando-o.

\section{Análise de dados}

A análise de dados, segundo Bogdan e Biklen (1994), caracteriza-se pela compreensão dos dados produzidos, permitindo apresentar os avanços teóricos e metodológicos destes. Assumiremos, então, uma perspectiva de busca de aspectos importantes inseridos nas amostras produzidas, devidamente organizadas de forma sistemática. Adentro a triangulação que propomos inicialmente, entre o problema, o sentido e o significado, atentaremos nossa análise para este entrelaçamento, que, em nossa concepção, é conduzido pelo sentido.

Consideramos importante relembrar que o significado, conforme Deleuze (2011), está associado à ideia de conceito. Dada a multiplicidade de pontos de vista que a associação com o conceito pode ter, atingindo uma dimensão rizomática (DELEUZE, 2011), focaremos na associação exclusiva com os conceitos matemáticos. Reconhecemos que se trata de um recorte (uma limitação), mas entendemos que a particularização, além de não contrariar a ideia principal, permite que tenhamos um olhar mais atento ao foco de nossa problemática, que é compreender os desdobramentos do problema apresentado pelos alunos.

Já o sentido, para Deleuze (2011), está associado diretamente ao problema. Embora o problema tenha sua fundamentação no virtual (Deleuze, 1988), o mesmo só pode ser observado por meio de suas atualizações, dadas pelos signos da fala e/ou por sua expressão imagética ou simbólica. Desse modo, nesse conjunto de análise, nos referimos ao já dito e manifestado a respeito do problema, que chamamos de aspectos objetivos do problema.

É sob essa perspectiva que buscaremos analisar as proposições que se referem ao problema trazido pelos alunos, desde sua primeira manifestação até a construção do modelo que o determinou. Esse movimento focará na busca por uma compreensão de como se deu o processo que associa a situação problema e a matemática.

Para o escopo deste artigo, faremos um recorte em nossa análise e focaremos apenas o processo ocorrido em um dos grupos que fizeram parte do processo investigativo. Esse grupo

\footnotetext{
${ }^{9}$ Camtasia Studio ${ }^{\circledR}$ é uma marca registrada TechSmith (informações disponívels em: < http://www.techsmith. $\mathrm{com} /$ camtasia.html $>$ ). Este software tem a finalidade de criar e editar vídeos, tanto capturados na tela do computador quanto em gravações externas.
} 
almejou a antecipação da receita da montagem de equipamentos elétricos, de uma empresa prestadora de serviços para o Polo Petroquímico. Para tanto, otimizaram o processo de montagem, primando pelos elementos que demandavam maior lucro para a empresa.

O projeto desenvolvido por esse grupo culminou no seguinte modelo matemático:

Função Objetivo (FO): Maximizar $\Sigma_{\mathrm{i}=1}^{7} \mathrm{x}_{\mathrm{i}} \mathrm{r}_{\mathrm{i}}$.

Onde $x_{i}$ é a porcentagem de cada tipo de material utilizado e $r_{i}$ sua respectiva receita, atribuída à unidade percentual da meta a ser atingida. A Função Objetivo busca uma maximização da captação de receitas, associadas diretamente ao lucro, e que leva em consideração a curva de metas já usada pela empresa, dada pelo índice EAP (Estrutura Analítica de Processo) que trabalha sobre 7 aspectos: Tubing $\left(\mathrm{x}_{1}\right)$, Cabo $\left(\mathrm{x}_{2}\right)$, Instrumento $\left(\mathrm{x}_{3}\right)$, Eletrocalha $\left(\mathrm{x}_{4}\right)$, Eletroduto $\left(\mathrm{x}_{5}\right)$, Caixas de Junção $\left(\mathrm{x}_{6}\right)$ e Painéis $\left(\mathrm{x}_{7}\right)$.

Cabe ressaltar que o grupo utilizou uma variação de $20 \%$ para os valores da porcentagem de cada tipo de material. Com isso, foram consideradas as seguintes restrições:

$$
\begin{aligned}
& 0,8 \mathrm{Px}_{1} \leq \mathrm{x}_{1} \leq 1,2 \mathrm{Px}_{1} \\
& 0,8 \mathrm{Px}_{2} \leq \mathrm{x}_{2} \leq 1,2 \mathrm{Px}_{2} \\
& 0,8 \mathrm{Px}_{3} \leq \mathrm{x}_{3} \leq 1,2 \mathrm{Px}_{3} \\
& 0,8 \mathrm{Px}_{4} \leq \mathrm{x}_{4} \leq 1,2 \mathrm{Px}_{4} \\
& 0,8 \mathrm{Px}_{5} \leq \mathrm{x}_{5} \leq 1,2 \mathrm{Px}_{5} \\
& 0,8 \mathrm{Px}_{6} \leq \mathrm{x}_{6} \leq 1,2 \mathrm{Px}_{6} \\
& 0,8 \mathrm{Px}_{7} \leq \mathrm{x}_{7} \leq 1,2 \mathrm{Px}_{7}
\end{aligned}
$$

Onde $\mathrm{Px}_{\mathrm{i}}$ é a meta percentual do mês de construção do elemento $\mathrm{x}_{\mathrm{i}}$.

Avaliando sob o ponto de vista somente matemático, este modelo é simples e direto. Entretanto, seu processo de construção envolveu uma gama de discussões, que avaliaremos sob a ótica das dimensões das proposições expressas pelos participantes. Neste contexto, adentro a problemática desenvolvida, selecionamos recortes das falas que entendemos encaminhar os aspectos matemáticos na determinação da referida função objetivo. Nos excertos, A1 é o Aluno 1, proponente do problema, A2 é o Aluno 2, participante do grupo, e P é o professor.

O primeiro excerto aborda uma situação que gira em torno da especificação do que será assumido como objetivo para maximização. No caso das falas, dois cenários são apresentados. O primeiro é a minimização de custos e o segundo a maximização de lucros. Esses aspectos podem ser observados no Excerto 1.

\title{
Excerto 1 - relação entre sentido e significado na escolha por caminhos nos fluxos de determinação
}

\author{
P (28'02"): O que tu tens que fažer para ganhar, on qual a tua programação para \\ ter o maior retorno financeiro? Bom, esse é teu problema. O que significa o retorno \\ financeiro? O menor custo ou... \\ A2 (28'27'): Mais lucro com menor [quantidade de] pessoas. \\ A1 (28'28'): É, o que eu já..., as pessoas eu tenho que usar as 85 , se eu não \\ usar as 85 , eles demitem gente. Eu tenho que demandar trabalho para as 85 pessoas.
}

Observando o Excerto 1, entendemos que a fala dada por A2 se mostra consonante com os conceitos relativos à Programação Linear (PL), que envolve a maximização ou mini- 
mização de uma função que pode ser expressa de modo linear. Conforme Moreira (2010), a Programação Linear é estruturada para resolver "[...] problemas que apresentem variáveis que possam ser medidas e cujos relacionamentos possam ser expressos por meio de equações e/ ou inequações lineares" (MOREIRA, 2010, p. 10), também chamadas de função objetivo (FO). De acordo com o objetivo da otimização, o modelo linear, respeitando as restrições impostas pela situação, poderá minimizar ou maximizar o resultado dessa função (MOREIRA, 2010). Associado à função objetivo, está um conjunto de restrições, que também podem ser expressas por equações e inequações lineares e dizem respeito às limitações a que o problema é submetido. Em termos matemáticos, tem-se que:

$$
\mathrm{z}=\sum_{\mathrm{i}=1}^{\mathrm{n}} a_{i} x_{i}
$$

Sujeito às equações e inequações que podem assumir a forma:

$$
\sum_{j=1}^{m} c_{j} x_{j} \leq d_{j} \text { e/ou } \sum_{l=1}^{p} e_{l} x_{l}=f_{l} \text { e/ou } \sum_{k=1}^{q} g_{k} x_{k} \geq h_{k}
$$

\section{Onde:}

z é a função objetivo;

n é o número de incógnitas;

$x_{i}$ é o número de variáveis consideradas;

$a_{i}, c_{j}, d_{j}, e_{l}, f_{l}, g_{k}, h_{k} \in \mathrm{R}$

$m, p, q<n$.

Embora essa segunda fala do Excerto 1 esteja carregada de significados matemáticos, associados aos conceitos e consequências lógicas permitidas pela matemática, o caminho que poderia ter sido seguido e consistia na redução das pessoas foi invalidado por A1. Por ser proponente do problema e vivenciá-lo no dia a dia, A1 logo apresentou a impossibilidade da opção, que pode ser observada de modo explícito quando diz: "[...] as pessoas, eu tenho que usar as 85 [...] Eu tenho que demandar trabalho para as 85 pessoas". Observando essas falas em relação ao nosso referencial, entendemos que essa invalidação se deu frente às especificidades do problema. Em outras palavras, dizemos que, embora o que A2 expressou tenha significado em termos lógicos, analisando a expressão frente ao problema, a mesma não faz sentido, pois a demissão de pessoas não está dentro do conjunto de soluções que efetivamente possam ser colocadas em prática. Desse modo, no processo de determinação de um problema, a significação matemática pode não ser o único aspecto levado em consideração ao optar por seguir um dos múltiplos caminhos/fluxos nos quais o problema pode se desdobrar.

Apesar da divisão de caminhos se mostrar, nesse caso, dicotômica, ao observar o fluxograma completo contendo todos os desdobramentos do problema (Figura 3), podemos visualizar toda a complexidade e multiplicidade que a situação assume.

Há de se considerar, nesta análise, a importância de a determinação fazer sentido ou não frente aos aspectos que envolvem o problema. Conforme Deleuze (2011), o sentido é próprio da proposição, insistindo e subsistindo nela. Entretanto, para avaliar o sentido, além de um vínculo forte com o problema, é preciso sempre outra proposição que, na especificidade do Excerto 1, foi dada por A1, quando diz "[...] Eu tenho que demandar trabalho para as 85 pessoas", 
invalidando, assim, a possibilidade de gerar lucro em função da diminuição de pessoas proposta por A2. É levando em consideração essa necessidade de haver sempre outra proposição para explicar o sentido que Deleuze (1988, p 152) diz “[...] nunca podemos dizer o sentido daquilo que dizemos".

Nesse primeiro excerto vimos como o sentido condiciona o processo de determinação do problema. No próximo excerto, veremos uma situação na qual o propositor do problema (Aluno A1) não estava presente. Esses aspectos podem ser observados no Excerto 2.

\section{Excerto 2 - Quando o proponente do problema não está presente}

Aluno 2: (00'12') Para distribuir a equipe e tal. Ai fizemos a restrição da equipe e a restrição da equipe conforme a obra.

Professor: (00’33”) Mas, por exemplo, essa aqui é a função minimizar custo, então tu tens... minimizar custo, mas não era para maximizar o valor das obras?

Aluno 2: (00'46") Mas dai a gente tinha trocado uma ideia, eu e tu, que a gente podia ou maximizar as obras, ou minimizar os custos, no caso de mão de obra.

Professor: (00'58') Falta o [Aluno 1], [...]. Porque tem que ver como isso é cobrado, pois pelo que ele me falou pode ser assim, não tem problema, dai precisa de custos, mas pelo que ele me falou tem que ter o que, ele tem que fazer as obras, todo o conjunto de obras de tal forma que tu tenhas o maior lucro possivel.

Professor (02'04"): Então uma tabela com os custos e uma tabela com os tempos de cada um, de tal forma que tu atendas o tempo. Agora, tem que pensar muito bem, eu quero fazer... pensem numa tabela de tempo também. Mas se eu quero..., a função objetivo tem que ser uma só: ou custos, ou lucros, ou tempos.

Aluno 2: (02’37’') O tempo gera mais dinheiro.

A função objetivo, construída pelos alunos e apresentada no início desta seção não representa apenas uma significação matemática, mas, sim, foi engendrada sistematicamente a partir de um objetivo claro e específico, apoiada nos aspectos definidos como constituintes do problema. O diálogo que trazemos agora envolveu o Aluno 2 e o professor. O Aluno 1, proponente do problema, não esteve presente no dia em que ocorreu essa conversa. Quando o Aluno 2 diz: "Para distribuir a equipe e tal. Ai fizemos a restrição da equipe e a restrição da equipe conforme a obra", mostra objetivos que não foram considerados no modelo final. Em termos temporais, a discussão acerca da redução de efetivo já tinha sido feita e descartada, pois não fazia sentido para o problema, conforme discutido no Excerto 1. Entretanto ela é novamente trazida, pois possui implicações importantes e, associada ao contexto matemático, facilmente implicaria otimização de processos. Essa proposição, portanto, está carregada de significados matemáticos implícitos. Mas, retomando as falas, as observações feitas sobre o Excerto 1 não apresentam sentido para o problema. 
Na sequência, o professor apresenta um conjunto de possibilidades: "função minimizar custo", "maximizar o valor das obras?', "maior lucro possivel”, finalizando com a expressão: “[...] a função objetivo tem que ser uma só: ou custos, ou lucros, ou tempos”. Isso mostra uma multiplicidade de caminhos, todos carregados novamente de significado, pois têm potencial de serem apreendidas pelos conceitos matemáticos. Embora essa multiplicidade tenha aspectos positivos, elas devem fazer sentido para o problema. Nesse caso, a ausência do propositor do problema foi sentida, pois havia a necessidade de uma validação da proposição por parte do mesmo. Esse aspecto é apresentado pelo professor, quando diz: "Falta o [Aluno 1], [...]. Porque tem que ver como isso é cobra$d o$ ". Evidentemente que o sentido, nesses casos, não deixaria de existir, pois ele insiste e subsiste na proposição (DELEUZE, 2011). O que entendemos ocorrer é que a falta do propositor, que vivencia o problema no seu dia a dia, pode encaminhar para uma espécie de desequilíbrio, no qual se abrem muitas possibilidades, todas carregadas de significado, mas dependentes de uma análise na qual a adoção ou não do caminho proporcionado pela proposição está relacionado com o sentido frente ao problema.

\section{Considerações finais}

Com a presente pesquisa, buscamos mostrar o entrelaçamento entre o sentido e o significado no processo de determinação do problema sobre a Modelagem Matemática, entendida por um processo dinâmico e não linear de formulação de modelos, em detrimento de algumas ideias metódicas e lineares encontradas na literatura. Apesar da dicotomia das visões, a concepção de problema se mostrou presente na sua maioria, fomentando a pergunta orientadora da pesquisa: Como se dá o processo de transformação da determinação do problema em Modelagem Matemática quando as situações investigadas partem das vivências dos estudantes? abarcando nossas ambições acerca da MM, discussão sobre o problema e a participação dos envolvidos no processo.

Apesar da multiplicidade do processo problemático, no primeiro excerto vimos uma certa estabilidade das determinações em direção aos objetivos lançados. Nesse contexto de que um "[...] problema não existe fora de suas soluções" (DELEUZE, 1988, p. 159), as proposições, sejam elas matemáticas ou objetivas, ganhavam certa estabilidade em direção a sua determinação, engendradas pelo sentido e seu entrelaçamento com os significados propostos. Já no segundo excerto, a relativa estabilidade proporcionada pela determinação da função objetivo foi abalada pela falta do propositor do problema, gerando desequilíbrio do processo problemático. Na nossa visão, o desequilíbrio não se configura como um erro processual, mas sim como um outro caminho, um outro vetor, factível de validação por parte dos envolvidos no processo, em direção à solução.

Em termos temporais, a partir do momento da definição do objetivo (o lucro), e do parâmetro a ser utilizado (a EAP), a construção da função objetivo, , foi delineada em função do sentido e do significado anteriormente expostos. Essa significação não está diretamente ligada a um conceito, conforme proposto por Deleuze (2011), mas sim a um parâmetro, e a sua tradução para uma significação matemática acontece na função objetivo.

O sentido não pode ser traduzido nem reduzido a uma proposição (DELEUZE, 2011, p. 20), pois é o “[...] expresso da proposição [...]”. Contudo, não há outra forma de explicitar o 
sentido senão por meio de sucessivas proposições (DELEUZE, 2011), logo, cada proposição dá o sentido para a seguinte, e, assim, sucessivamente. O sentido, então, será o próprio acontecimento, tendo como vetor de solução o objetivo, que é o lucro, e um limitador físico, caracterizado pelo índice EAP. Mas, de forma alguma o sentido estancará as possibilidades de solução, ele atuará na construção dos modelos matemáticos seguintes não se reduzindo “[...] aos estados das coisas individuais, às imagens particulares, às crenças pessoais e aos conceitos universais e gerais" (DELEUZE, 2011, p. 20), integrando-os de forma indissociável, rizomática. Nesse contexto, o sentido não surge para explicitar as proposições, mas sim fomentar seus desdobramentos, unindo as dimensões classificatórias em direção à determinação do problema, não confundindo seu processo problemático com sua determinação.

A relação, inicialmente dicotômica, entre o problema e a matemática é total, pois ambos estão no âmbito virtual (DELEUZE, 1998, 2011). A associação de ambos é proporcionada pela $\mathrm{MM}$ e, para que isso aconteça, a proposição do problema deve possuir significações que podem ser "apreendidas" pela matemática, mantendo as características problemáticas. Esta "apreensão" é proporcionada pelo sentido e fomentada pelos envolvidos no processo: os alunos e o professor, ao longo de um processo de construção de modelos que visam resolver situações problemáticas trazidas pelos próprios alunos. Nesse contexto, o professor, juntamente com os alunos pode assumir um papel mais evidente diante das significações. Entretanto o professor deve contar com um processo dialógico de busca por sentido feito juntamente com os alunos, em especial não sendo o proponente do problema, como foi o caso da pesquisa desenvolvida.

Em suma, focamos a análise nas especificidades da determinação do problema, mais precisamente como essas determinações fizeram sentido para o problema dos estudantes. Entretanto, percebemos que os dados indicaram outros aspectos que podem influenciar, apresentados principalmente pelas características subjetivas do problema. É nesse sentido que pretendemos avançar nossa pesquisa, buscando um entendimento acerca da determinação dos problemas e sua relação com o processo de Modelagem Matemática no âmbito da Educação Matemática.

Para o prosseguimento da pesquisa, entendemos que ainda existem lacunas a serem preenchidas acerca do entendimento do processo de Modelagem Matemática. A própria definição deleuziana sobre problema não permite que sua determinação se confunda com sua solução, diferindo-se por sua natureza. E, sabendo que sua determinação engendra a problemática em direção à solução (DELEUZE, 1988), procuraremos nos aprofundar no conceito de gênese do referido autor, buscando aspectos que podem influenciá-la e engendrá-la na imanência do pensamento.

\section{Referências}

ABBAGNANO, N. Dicionário de filosofia. São Paulo: Martins Fontes, 2007.

ANASTACIO, M. Q. A. Considerações sobre modelagem matemática e a educação matemática. 1990. 100 f. Dissertação (Mestrado em Educação Matemática) - Instituto de Geociências e Ciências Exatas, Universidade Estadual Paulista, Rio Claro, 1990. 
Weingarten, T.; Dalla Vecchia, R.

ARAÚJO, J. L. Cálculo, tecnologias e modelagem matemática: as discussões dos alunos. 2002. 173 f. Tese (Doutorado em Educação Matemática) - Instituto de Geociências e Ciências Exatas, Universidade Estadual Paulista, Rio Claro, 2002.

BASSANEZI, R. C. Ensino-aprendizagem com modelagem matemática. 2. ed. São Paulo: Contexto, 2004.

BAUDRILLARD, J. Simulacro e simulação. Lisboa: Relógio d’Água, 1991.

BIEMBENGUT, M. S.; HEIN, N. Modelagem matemática no ensino. São Paulo: Contexto, 2007.

BICUDO, M. A. V.; ROSA, M. Realidade e cibermundo: horizontes filosóficos e educacionais antevistos. Canoas: Editora da ULBRA, 2010.

BOGDAN, R; BIKLEN, S. Investigação qualitativa em educação: uma introdução à teoria e aos métodos. Porto: Porto Editora, 1994.

DALLA VECCHIA, R. A modelagem matemática e a realidade do mundo cibernético. 2012. 275 f. Tese (Doutorado em Educação Matemática) - Instituto de Geociências e Ciências Exatas, Universidade Estadual Paulista, Rio Claro, 2012.

DALLA VECCHIA, R.; MALTEMPI, M. V. Modelagem matemática e tecnologias de informação e comunicação: a realidade do mundo cibernético como um vetor de virtualização. Bolema: boletim de educação matemática, v. 26, n. 43, p. 963-990, 2012.

Disponível em: <https://doi.org/10.1590/S0103-636X2012000300010>. Acesso em: 4 jan. 2017.

DELEUZE, G. Diferença e repetição. São Paulo: Graal, 1988.

. Lógica do sentido. 4. ed. São Paulo: Perspectiva, 2011.

FERRI, R. B.; BLUM; W. Insights into teachers' unconscious behaviour in modeling contexts. In: LESH, R. et al. (Ed.). Modeling students' mathematical modeling competences. New York: Springer, 2010. p. 423-432.

GAMBOA, S. S. Pesquisa em educação: métodos e epistemologias. 2. ed. Chapecó: Argos, 2012.

KAISER, G.; SRIRAMAN, B. A global survey of international perspectives on modelling in mathematics education. ZDM: mathematics education, Heidelberg, v. 38, n. 3, p. 302-310, 2006. Disponível em: <https://doi.org/10.1007/BF02652813>. Acesso em: 4 jan. 2017.

KAISER, G.; SCHWARZ, B.; TIEDEMANN, S. Future teachers' professional knowledge on modeling. In: LESH, R. et al. (Ed.). Modeling students' mathematical modeling competences. New York: Springer, 2010. p. 433-444.

KLÜBER, T. Uma metacompreensão da modelagem matemática na educação matemática. 2012. Tese (Doutorado em Educação Científica e Tecnológica) - Universidade Federal de Santa Catarina, Florianópolis, 2012. 
MALTEMPI, M. V.; DALLA VECCHIA, R. About mathematical modeling in the reality of the cybernetic world. In: CONGRESS OF EUROPEAN RESEARCH IN MATHEMATICS EDUCATION (CERME), 8., 2013, Antalya. Proceedings... Disponível em: <http://www.mathematik.uni-dortmund.de/ erme/doc/CERME8/CERME8_2013_ Proceedings.pdf $>$. Acesso em: 4 jan. 2017.

MOREIRA, D. A. Pesquisa operacional: curso introdutório. São Paulo: Thomson Learning, 2010.

RAMOS, A. Metodologia da pesquisa científica: como uma monografia pode abrir o horizonte para o conhecimento. São Paulo: Atlas, 2009.

WEINGARTEN, T. Modelagem matemática: um enfoque na transformação da determinação do problema. 2015. Dissertação (Mestrado em Educação Matemática) Universidade Luterana do Brasil, Canoas, 2015.

WEINGARTEN, T.; DALLA VECCHIA, R. O sentido e o significado no processo de determinação de problemas num contexto de modelagem matemática. In: CONFERENCIA INTERAMERICANA DE EDUCACIÓN MATEMÁTICA (CIAEM), 14., 2015, Tuxtla Gutiérrez. Memorias... Colonia Cuauhtémoc: Comité Interamericano de Educación Matemática, 2015. v. 16, p. 140-149. Disponível em: <http://ciaem-redumate.org/memoriasciaem/xiv/pdf/Vol16Model.pdf>. Acesso em: 4 jan. 2017.

Artigo recebido em 08/09/2015. Aceito em 13/06/2016.

Endereço para contato: Universidade Luterana do Brasil (ULBRA), Av. Farroupilha, 8001, Prédio 14, sala 338, bairro São José, CEP 92425-000, Canoas, RS, Brasil. 